\title{
Role of Antiplatelet Therapy in Pediatric Stroke with Mineralizing Angiopathy
}

\author{
Mahesh Kamate $^{1}$ D $\cdot$ Neha Goudar $^{1} \cdot$ Mayank Detroja $^{1}$
}

Received: 20 May 2021 / Accepted: 16 July 2021 / Published online: 7 August 2021

(c) Dr. K C Chaudhuri Foundation 2021

To the Editor: Mineralizing angiopathy (MA) is emerging as a common cause of stroke in otherwise healthy children less than 3-4 y of age [1]. Extrapolating the data from other causes of stroke in children, many physicians prescribe antiplatelet drugs like aspirin for 1-2 y. However, there is no theoretical basis for use of aspirin in MA, as there is no arteriopathy/on-going inflammation or a prothrombotic condition in MA. Hence as a policy, from 2017 onwards, we did not treat children with antiplatelet drugs other than supportive care.

A total of 17 children out of 54 cases of arterial ischemic strokes had a diagnosis of MA in the last $8 \mathrm{y}$. While 6 of 17 children, who presented before 2017 had received aspirin for varying periods ranging from 2 to 18 mo duration, 11 children, who presented after 2017 were not given any antiplatelet therapy. The mean follow-up age was $50.3 \mathrm{mo}$ (range: 12-96 mo). None of the children had stroke recurrence whether they received or did not receive antiplatelet therapy.

In the study by Lingappa et al., all 22 children with MA were treated with aspirin and were followed up for a mean duration of 11 mo. Five of these experienced stroke recurrences while on aspirin therapy [2]. In a similar study conducted by Goraya et al., all infants with acute stroke associated with MA were treated with low-molecular-weight heparin succeeded by aspirin for 12-mo. None had stroke recurrence [3]. Yang et al. found that only 1 out of the 13 children with basal ganglia infarct presented with recurrent stroke following minor head trauma despite no aspirin therapy [4]. In our study also, none had recurrence of stroke irrespective of antiplatelet therapy. Therefore, probably there is no role of antiplatelet therapy in MA. Further studies are needed in this direction.

\section{Declarations}

Conflict of Interest None.

\section{References}

1. Jain P, Kishore P, Bhasin JS, Arya SC. Mineralizing angiopathy with basal ganglia stroke in an infant. Ann Indian Acad Neurol. 2015;18:233-4.

2. Lingappa L, Varma RD, Siddaiahgari S, Konanki R. Mineralizing angiopathy with infantile basal ganglia stroke after minor trauma. Dev Med Child Neurol. 2014;56:78-84.

3. Goraya JS, Berry S, Saggar K, Ahluwalia A. Stroke after minor head trauma in infants and young children with basal ganglia calcification: a lenticulostriate vasculopathy? J Child Neurol. 2018;33:146-52.

4. Yang FH, Wang H, Zhang JM, Liang HY. Clinical features and risk factors of cerebral infarction after mild head trauma under 18 months of age. Pediatr Neurol. 2013;48:220-6.

Publisher's Note Springer Nature remains neutral with regard to jurisdictional claims in published maps and institutional affiliations.
Mahesh Kamate

drmaheshkamate@gmail.com

1 Department of Pediatric Neurology, KAHER's Jawaharlal Nehru Medical College, Belagavi, Karnataka 590010, India 